\title{
Model Predictive Control of Two-Area Load Frequency Control Based Imperialist Competitive Algorithm
}

\author{
M. Elsisi ${ }^{11}$, M. A. S. Aboelela ${ }^{2}$, M. Soliman ${ }^{3}$, W. Mansour ${ }^{4}$ \\ ${ }^{1,3,4}$ Electrical Power and Machines Department, Faculty of Engineering (Shoubra), Benha University, \\ Cairo, EGYPT, 108 Shoubra St., B.O. Box 11241, Tel.: +20 01011793910 \\ ${ }^{2}$ Electrical Power and Machines Department, Faculty of Engineering, Cairo University, Giza, Egypt \\ *Corresponding author, e-mail: elsisimahmoud22@yahoo.com ${ }^{1}$, magdysafaa@yahoo.com², \\ msoliman_28@yahoo.com ${ }^{3}$, wagdy_ibrahim2010@yahoo.com ${ }^{4}$
}

\begin{abstract}
Imperialist Competitive Algorithm (ICA) has recently been explored to develop a novel algorithm for distributed optimization and control. This paper proposes a Model Predictive Control (MPC) of Load Frequency Control (LFC) based ICA to enhance the damping of oscillations in a two-area power system. A two-area non-reheat thermal system is considered to be equipped with Model Predictive Control (MPC). ICA is utilized to search for optimal controller parameters by minimizing a time-domain based objective function. The performance of the proposed controller has been evaluated with the performance of the conventional PI controller, and PI controller tuned by ICA in order to demonstrate the superior efficiency of the proposed MPC tuned by ICA. Simulation results emphasis on the better performance of the optimized MPC based on ICA in compare to optimized PI controller based on ICA and conventional one over wide range of operating conditions, and system parameters variations.
\end{abstract}

Keywords: imperialist competitive algorithm, load frequency control, model predictive control

Copyright $(2015$ Institute of Advanced Engineering and Science. All rights reserved.

\section{Introduction}

Frequency control, during the load and generation imbalance, represents a very imperative issue for large-scale power systems. Automatic generation control (AGC) plays a significant role in the power system by maintaining the scheduled system frequency and tie-line power flow during normal operating conditions and during small perturbations [1-3]. This function of an AGC is always referred to as "load frequency control (LFC)" as mentioned by Kundur [2]. LFC is often considered as one of the first and foremost large-scale, decentralized, robust controllers in engineering practice. LFC is accomplished by two different control actions of the primary speed control and supplementary speed control in an interconnected power system.

Several approaches such as optimal, genetic algorithm (GA), particle swarm optimization (PSO), bacterial foraging optimization (BFO), etc., for the design and optimization of the LFC system, have been reported in the literature [4-15]. Modern optimal control concept for AGC designs of interconnected power system was firstly presented by Elgerd and Fosha [45]. Genetic algorithms (GAs) have been extensively considered for the design of AGC. Optimal integral gains and optimal PID control parameters have been computed by GAs technique for an interconnected, equal non-reheat and reheat type two generating areas [6-7]. In [8] the Parameters of PID sliding-mode used in LFC of multi area power systems with nonlinear elements are optimized by GA. In [9], GA is used to compute the decentralized control parameters to achieve an optimum operating point for a realistic system comprising generation rate constraint (GRC), dead band, and time delays. The use of particle swarm optimization (PSO) for optimizing the parameters of AGC, where an integral controller and a proportionalplus-integral controller, is reported in [10]. In [11] the parameters of PI controller are designed by PSO with the new cost function and compared their results with [10]. In [12], a robust PID controller based ICA used for LFC application. The authors of [13-14] have proposed bacterial foraging optimization algorithm (BFOA) for designing PI and PID-based load frequency controller for two-area power system with and without GRC. In [15] a new optimization algorithm based on the law of gravity and mass interactions is introduced. In the algorithm, the searcher 
agents are a collection of masses which work with each other based on the Newtonian gravity and the laws of motion.

Model Predictive Control (MPC) is improved considerably in the last decades in field of control. It has a lot of advantages such as fast response, and stability against nonlinearities, constraints and parameters uncertainties [16]. In [17-21] some applications of MPC on LFC.

This paper proposes the ICA for optimal tuning of MPC controllers in two area interconnected power system to damp power system oscillations. The MPC control design is formulated as an optimization problem and ICA is employed to search for optimal controller parameters by minimizing a candidate time-domain based objective function. The performance of the proposed MPC-based ICA is evaluated by comparison with PI-based ICA. Simulations results on a two-area test system are presented to assure the superiority of the proposed method compared with PI-based ICA and conventional one.

\section{Imperialist Competitive Algorithm}

Imperialist Competitive Algorithm (ICA) is a novel artificial intelligence technique that uses imperialistic competition process. This algorithm starts randomly with an initial population. In this algorithm a country represent an individual of the population. Some of the best countries are chosen to be the imperialist states and all the other countries form the colonies of these imperialists. the colonies of initial population are divided among the imperialists based on their fitness. After this step, these colonies start moving toward their relevant imperialist country $[22,23]$. Figure 1 shows the flowchart of the ICA. Figure 2 shows the movement of a colony to its relevant imperialist. In this motion, $\theta$ and $x$ are selected randomly with uniform distribution as demonstrated in (1) and (2).

$$
\begin{aligned}
& x \cong u(0, \beta \times d) \\
& \theta \cong u(-\gamma, \gamma)
\end{aligned}
$$

Where $\beta$ is a number higher than $1, d$ is the distance between colony and imperialist and $y$ is a limit angle that adjusts the deviation from the original direction [23]. In this paper the values of $\beta$ and $y$ are selected 2 and $\pi / 4$ (Rad) respectively.

\section{Model Predictive Controller}

Model Predictive Control (MPC) has been proved as an effective and accepted control strategy to stabilize dynamical systems in the presence of nonlinearities, uncertainties, constraints and delays, especially in process industries [17-21]. A MPC scheme is shown in Figure 3. As shown, the MPC consists of prediction and controller unit. The prediction unit forecast future behavior of system depend on its current output, disturbance and control signal on a finite prediction horizon. The control unit uses the predicted output in minimizing the objective function in presence of system constraints. There are a lot of formulations of the MPC that are different either in a formulation of the objective function [16, 24]. In the MPC the measured disturbance can be compensated by the method of feed forward control. Unlike feedback controller, feed forward control rejects the measured disturbance before affect on the system. Feed-forward control used in association with feedback control; the feedforward control reject most of the measured disturbance effect, and the feedback control reject the rest as well as dealing with unmeasured disturbances. More details of this control method could be found in [24]. 


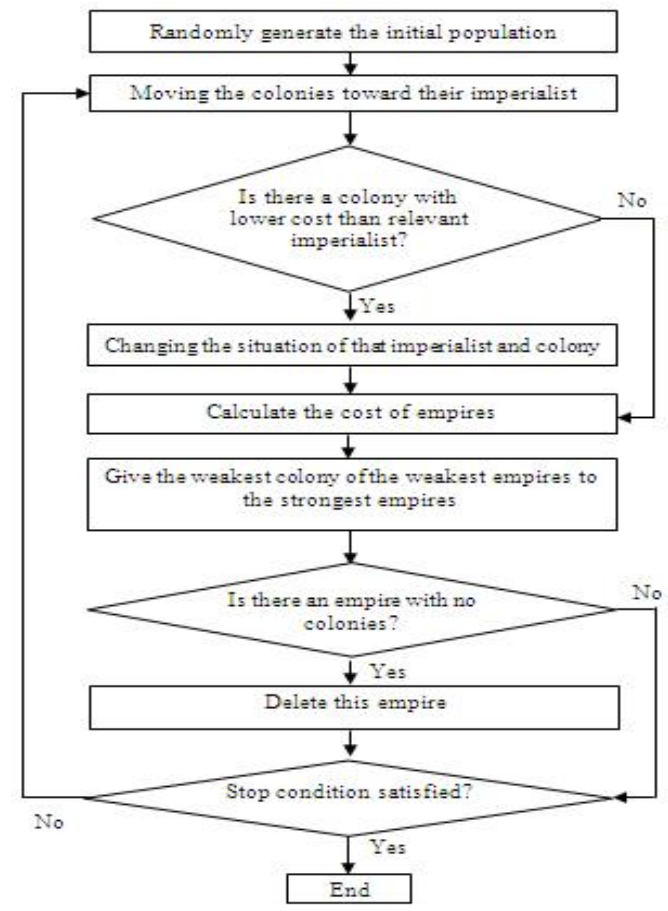

Figure 1. Flowchart of the ICA

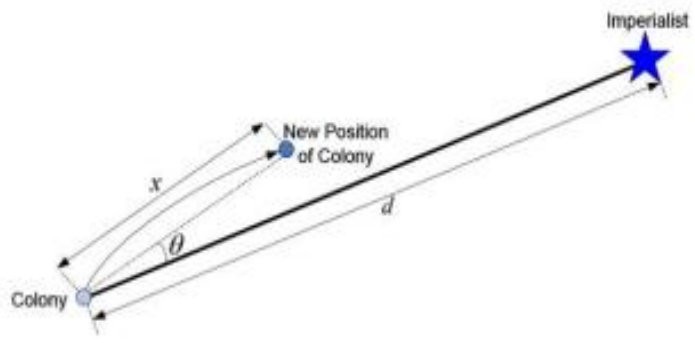

Figure 2. Colonies movement into their relevant imperialist

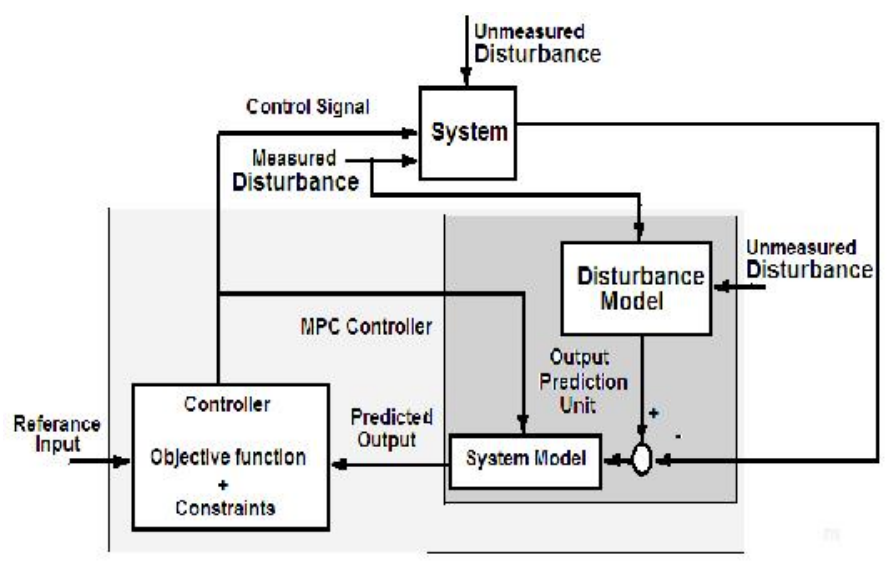

Figure 3. A general MPC scheme

\section{Two Area Power System}

A model of controlled non-reheat thermal plants in two-area interconnected power system is shown in Figure 4 where $f_{i}$ is the system frequency $(\mathrm{Hz}), R_{i}$ is the regulation constant (Hz/unit), $T_{G i}$ is the speed governor time constant (s), $T_{T i}$ is the turbine time constant (s) and $T_{P i}$ is the power system time constant (s), $A C E_{i}$ is the area control error, $\triangle P_{D i}$ is the load demand change, $\Delta P_{c i}$ is the change in speed changer position, $\Delta P_{G i}$ is the change in governor valve position, $K_{P i}$ is the power system gain, and $\Delta P_{t i e}$ is the change in tie line power. The overall system can be modeled as a multivariable system in the following form:

$$
\begin{aligned}
& \dot{x}=A x+B u+\Gamma d, \\
& y=c x
\end{aligned}
$$




$$
\begin{aligned}
& x=\left[\begin{array}{lllllllll}
\Delta f_{1} & \Delta P_{T 1} & \Delta P_{G 1} & \Delta P_{C 1} & \Delta P_{\text {tie }} & \Delta f_{2} & \Delta P_{T 2} & \Delta P_{G 2} & \Delta P_{C 2}
\end{array}\right]^{T} \\
& u=\left[\begin{array}{ll}
u_{1} & u_{2}
\end{array}\right]^{T}, y=\left[\begin{array}{ll}
A C E & A C E_{2}
\end{array}\right]^{T}, d=\left[\begin{array}{ll}
\Delta P_{D 1} & \Delta P_{D 2}
\end{array}\right]^{T}
\end{aligned}
$$

For the two area considered in this study, the conventional integral controller was replaced by a MPC controller. The MPC controllers in both areas are considered identical and the control signal within range, $-0.1 \leq \mathrm{Ui} \leq 0.1$.

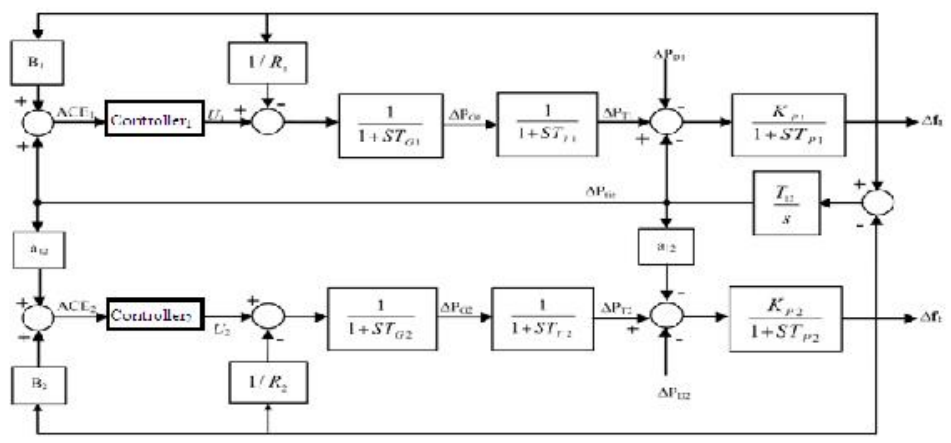

Figure 4. Two-area interconnected power system

\section{Model Predictive Load Frequency Control}

MPC controller has been used to generate the control signal based on $A C E_{i}, P_{D i}$ and reference value of $A C E_{i}$ as its inputs. Where reference value of $A C E_{i}$ equal zero. A model predictive load frequency control scheme is shown in Figure 5.

In this paper the MPC toolbox in Matlab Simulink has been used to design an MPC controller. The controller design requires a Linear Time Invariant (LTI) model of the system that is to be controlled. The rate at which MPC operates is $1 / N T_{S}$, where $T_{S}$ is sampling period, $N$ is the number of controls that are applied to the system. In most cases, $N$ is chosen equal one. The value of $T_{S}$ is important because it is the length of each prediction step. The method for selecting $T_{\mathrm{S}}$ for this problem is based on tracking performance. Selecting the prediction horizon $\mathrm{P}$ and control horizon $M$ were also affected by the controller. Weights $(Q$ and $R$ ) on system's input and output are chosen at their best quantities. The ICA is proposed in this paper to get the best value of $T_{S}, P, M$ and weights on system's input and output.

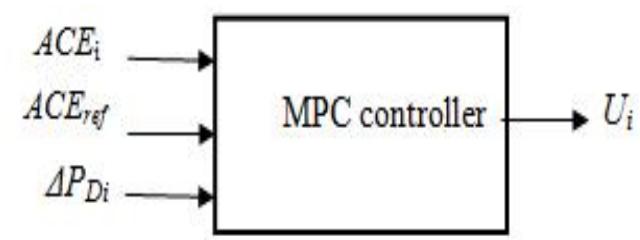

Figure 5. A model predictive load frequency control scheme

$$
J=\int_{0}^{T} t\left(\left|\Delta f_{1}\right|+\left|\Delta f_{2}\right|+\left|\Delta P_{\text {tie }}\right|\right) d t
$$

Where $T$ is the simulation time.

This study focuses on optimal tuning of controllers for LFC using ICA. The aim of the optimization is to search for the optimum controller parameters of MPC that improve the damping characteristics of the system under all operating conditions and various loads and finally designing a low order controller for easy implementation. 


\section{Simulation Results}

In this section different comparative cases are examined to show the effectiveness of the proposed ICA method for optimizing controller parameters of MPC. Table 1 gives the optimum values of controller parameters for different methods. The PI controller parameters of conventional controller due to [13].

Table 1. Controller Parameters and Objective Function (J).

\begin{tabular}{cccl}
\hline & $\begin{array}{c}\text { Conventional } \\
\mathrm{PI}\end{array}$ & GSA-PI & $\mathrm{MPC}$ \\
\hline Controller & $\mathrm{K}_{\mathrm{p}}=0.7005$, & $\mathrm{K}_{\mathrm{p}}=-0.3140$, & $\mathrm{Ts}=0.1906$, \\
Parameters & $\mathrm{K}_{\mathrm{l}}=0.3802$ & $\mathrm{~K}_{\mathrm{l}}=0.4578$ & $\begin{array}{l}\mathrm{P}=2, \mathrm{M}=2, \\
\mathrm{Q}=3.8041,\end{array}$ \\
& & & $\begin{array}{l}\mathrm{R}=1.1918 \\
\mathrm{~J}\end{array}$ \\
& 3.5795 & 1.1764 & 0.1955 \\
\hline
\end{tabular}

\subsection{Step Increase in Demand of the First Area $\left(\Delta P_{D 1}\right)$}

In this case, a 0.1 step increase in demand of the first area $\left(\Delta P_{D_{1}}\right)$ is applied (nominal test case). The change in frequency of the first area $\Delta \mathrm{f}_{1}$, the change in frequency of the second area $\Delta f_{2}$, and change in tie-line power of the closed loop system are shown in Figure 6-8. Remarkably, the response with conventional $\mathrm{PI}$ controller has high settling time and undesirable oscillations. Also compared with PI-based ICA the proposed method is indeed more efficient in improving the damping characteristic of power system.

\subsection{Step Increase in Demand of the Second Area $\left(\Delta P_{D 2}\right)$}

In this case, a 0.1 step increase is applied as a change of demand in the second area $\left(\Delta P_{D 2}\right)$. The change in frequency of the first area $\Delta f_{1}$, the change in frequency of the second area $\Delta f_{2}$ and change in tie-line power of the closed loop system are shown in Figure 9-11. From these Figures it can be seen that oscillations are disappear in the presence of the proposed controller. Moreover, the proposed method outperforms and outlasts PI-based ICA in damping oscillations effectively and reducing settling time. Hence compared to the conventional controller, and PI-based ICA, MPC based ICA greatly enhances the system stability and improves the damping characteristics of power system.

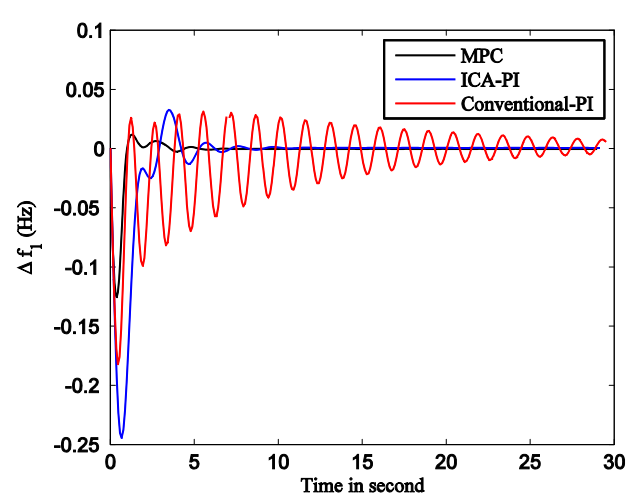

Figure 6. Change in $f_{1}$ for $0.1 p . u$ step increment in $\mathrm{P}_{\mathrm{D} 1}$

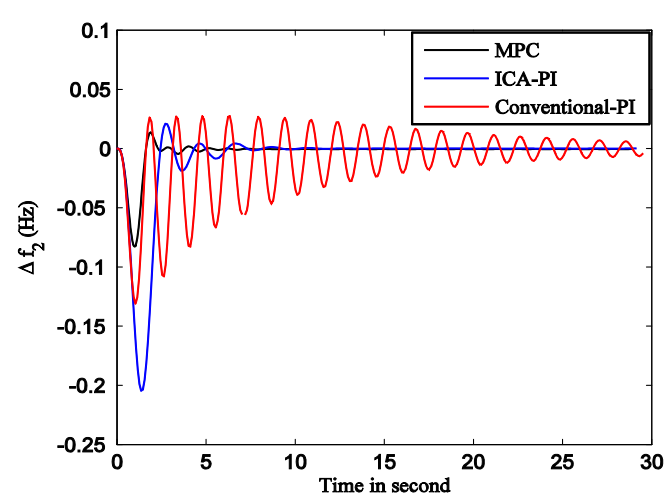

Figure 7. Change in $f_{2}$ for $0.1 p . u$ step increment in $\mathrm{P}_{\mathrm{D} 1}$ 


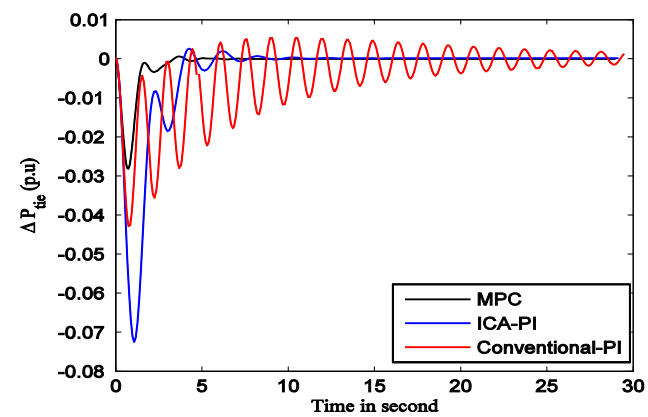

Figure 8. Change in $P_{\text {tie }}$ for 0.1p.u step increment in $P_{D 1}$

\subsection{Step Increase in Demand of the First and Second Area Simultaneously}

In this case, a $10 \%$ step increase in demand of the first area $\left(\Delta \mathrm{P}_{\mathrm{D} 1}\right)$ and second area $\left(\Delta \mathrm{P}_{\mathrm{D} 2}\right)$ simultaneously are applied. It is clear from Figure 12 that the proposed method has a smaller settling time and system response is quickly driven back to zero compared with conventional controller and PI-based ICA In addition, the potential and superiority of the proposed method over the conventional, and PI-based ICA is demonstrated.

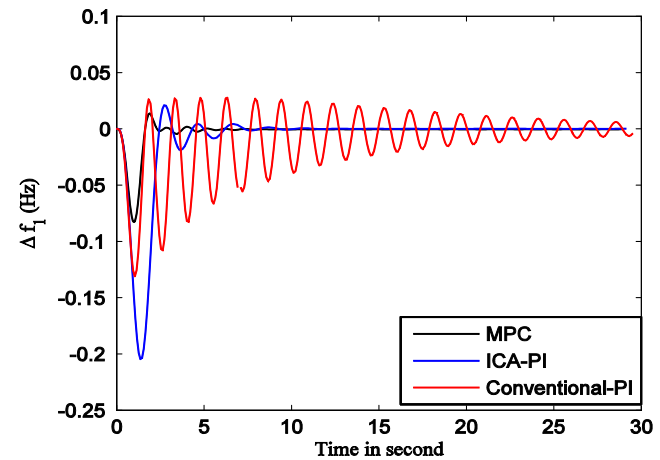

Figure 9. Change in $f_{1}$ for 0.1 p.u step increment in $\mathrm{P}_{\mathrm{D} 2}$

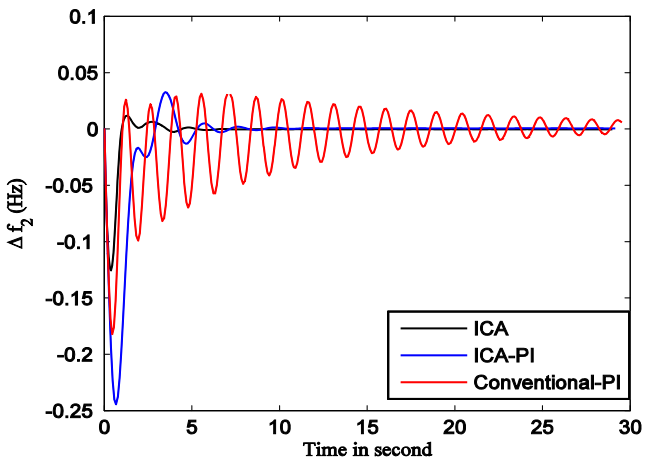

Figure 10. Change in $\mathrm{f}_{2}$ for 0.1 p.u step increment in $\mathrm{P}_{\mathrm{D} 2}$

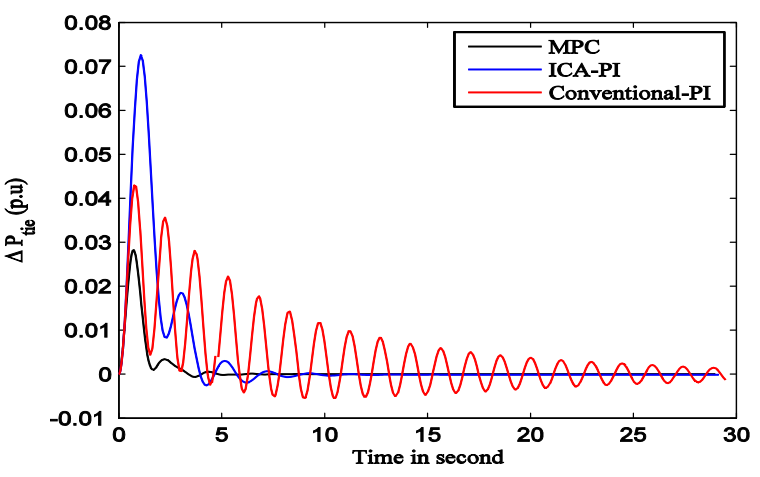

Figure 11. Change in $P_{\text {tie }}$ for $0.1 p . u$ step increment in $P_{D 2}$

\subsection{Parameter Variation}

A parameter variation test is also applied to validate the robustness of the proposed controller. Figure 13 shows the change in frequency of first area with variation in $T_{12}$. It is clear that the system stable with the proposed controller. 


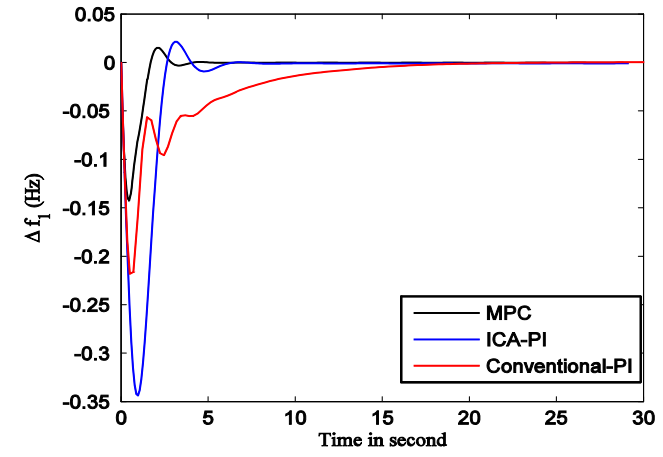

Figure 12. Change in $f_{1}$ for 0.1 p.u step increment in $\mathrm{P}_{\mathrm{D} 1}$ and $\mathrm{P}_{\mathrm{D} 2}$

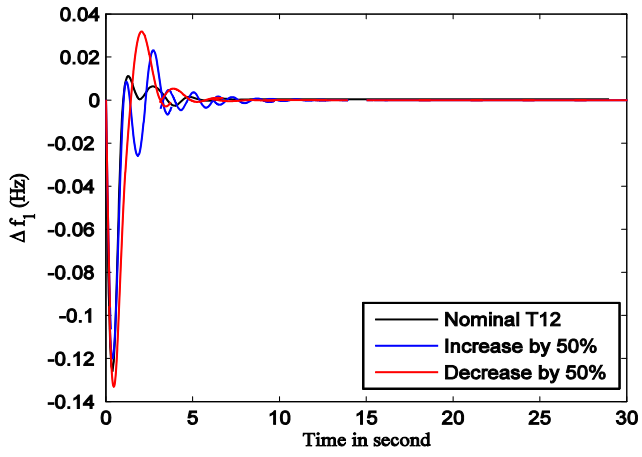

Figure 13. Change in $f_{1}$ due to $\pm 50 \%$ perturbation in $\mathrm{T}_{12}$

\section{Conclusion}

This paper presents the application of the ICA algorithm as a new artificial intelligence technique in order to optimize the AGC in a two-area interconnected power system. ICA algorithm is proposed to tune the parameters of MPC controller. A two-area power system is considered to demonstrate the proposed method. Simulation results emphasis that the designed MPC-based ICA is robust in its operation and gives a superb damping performance for frequency and tie line power deviation compared to conventional PI controller, and PI-based ICA. Besides the simple architecture of the proposed controller it has the potentiality of implementation in real time environment.

\section{References}

[1] P Kundur. Power system stability and control. McGraw-Hill. 1994.

[2] H Saadat. Power system analysis. Tata Mcgraw-Hill. 2002.

[3] VK Kamboj, K Arora, P Khurana. Automatic Generation Control for Interconnected Hydro-thermal System with the help of Conventional Controllers. International Journal of Electrical and Computer Engineering (IJECE). 2012; 2(4): 547-552.

[4] OI Elgerd, CE Fosha. Optimum megawatt-frequency control of multiarea electric energy systems. IEEE Trans. Power App. Syst. 1970; 4: 556-563.

[5] CE Fosha, OI Elgerd. The megawatt-frequency control problem-A new approach via optimal control theory. IEEE Trans. Power App. Syst. 1970; 4: 563-577.

[6] SP Ghoshal, SK Goswami. Application of GA based optimal integral gains in fuzzy based active power-frequency control of nonreheat and reheat thermal generating systems. Elect. Power Syst. Res. 2003; 67: 79-88.

[7] SP Ghoshal. Application of GA/GA-SA based fuzzy automatic generation control of a multi-area thermal generating system. Elect. Power Syst. Res. 2004; 70: 115-127.

[8] Li Pingkang, Zhu Hengjun, Li Yuyun. Genetic algorithm optimization for AGC of multi-area power systems. TENCON'02. Proceedings. 2002 IEEE Region 10 Conference on Computers, Communications, Control and Power Engineering. 2002; 3.

[9] H Golpira, H Bevrani. Application of GA optimization for automatic generation control design in an interconnected power system. Energy Conversion and Management. 2011; 52(5): 2247-2255.

[10] YL Abdel-Magid, MA Abido. AGC tuning of interconnected reheat thermal systems with particle swarm optimization. Proc. of the $200310^{\text {th }}$ IEEE international conference on electronics, circuits and systems. 2003; 1: 376-379.

[11] H Gozde, MC Taplamacioglu, I Kocaarslan, MA Senol. Particle swarm optimization based PI-controller design to load-frequency control of a two area reheat thermal power system. J Therm Sci Technol. 2010; 30(1): 13-21.

[12] H Shabani, B Vahidi, M. Ebrahimpour. A robust PID controller based on imperialist competitive algorithm for load-frequency control of power systems. ISA Trans. 2013; 52(1): 88-95.

[13] ES Ali, SM Abd-Elazim. Bacteria foraging optimization algorithm based load frequency controller for interconnected power system. Int. J Electr. Power Energy Syst. 2011; 33(3): 633-638.

[14] ES Ali, SM Abd-Elazim. BFOA based design of PID controller for two area Load Frequency Control with nonlinearities. Electrical Power and Energy Systems. 2013; 51: 224-231. 
[15] M Elsisi, M Soliman, MAS Aboelela, W Mansour. Dual Proportional Integral Controller of Two-Area Load Frequency Control Based Gravitational Search Algorithm. TELKOMNIKA Indonesian Journal of Electrical Engineering. 2015; 15(1): 26-35.

[16] E Camacho, C Bordons. Model Predictive Control. 2nd ed. Berlin, Germany: Springer. 2004.

[17] D Rerkpreedapong, N Atic, A Feliachi. Economy oriented model predictive load frequency control. In Proc. 2003 Power engineering conf. on large engineering systems. 2003: 12-16.

[18] N Atic, A Feliachi, D Rerkpreedapong. CPS1 and CPS2 Compliant Wedge-Shaped Model Predictive Load Frequency Control. Power engineering society general meeting. 2004; 1: 55-60.

[19] L Kong, L Xieo. A New Model Predictive Control Scheme-based load frequency control. In Proc. 2007 IEEE International Conf on Cntrl and Automation. 2007: 2514-2618.

[20] AN Venkat, IA Hiskens, JB Rawlings, SJ Wright. Distributed MPC strategies with application to power system automatic generation control. IEEE Trans Control Syst Technology. 2008; 16(6): 1192-1206.

[21] TH Mohamed, H Bevrani, AA Hassan, T Hiyama. Decentralized model predictive based load frequency control in an interconnected power system. Energy Convers Manage. 2011; 52(2): 12081214.

[22] E Atashpaz-Gargari, C Lucas. Imperialist competitive algorithm: an algorithm for optimization inspired by imperialistic competition. In Evolutionary Computation, 2007. CEC 2007, IEEE Congress. 2007: 4661-4667.

[23] E Atashpaz-Gargari, C Lucas. Designing an optimal PID controller using Imperialist Competitive Algorithm. In First Joint Congress on Fuzzy and Intelligent Systems Ferdowsi University of Mashhad, Iran. 2007: 29-31.

[24] JM Maciejowski. Predictive control with constraints. Prenctice Hall. 2002. 